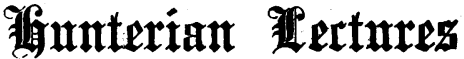

ON

THE SURGERY OF THE LYMPHATIC
SYSTEM.

BY

W. SAMPSON HANDLEY, M.S., F.R.C.S., CONTERIAN PROFESSOR, ROYAL COLLEGE OF SURGEONS OF ENGLAND; ASSISTANT SURGEON TO THE MIDDLESEX HOBPITAL, SURGEON TO THE BOLINGBROKE HOSPITAL.

\section{LECTURE I}

Mr. President, Ladies, and Gentlemen,-Although for the sake of brevity I have chosen an inclusive title for these lectures, you will hardly expect a complete survey of such a wide field. I propose to exclude the lymphatic glands from consideration and to deal only with the growing edge of my subject-the surgery of the lymphatic ressels and spaces.

My principal theme will be the surgery of dropsy, using this term as defined by Professor Starling to denote "either an increased amount of fluid in the connective tissue spaces, which is sometimes designated anasarca or oedema, or an accumulation of fluid in the serous spaces of the body, as in the conditions of hydrothorax and mscites."

The subject of lymphatic anatomy, which necessarily forms the basis of lymphatic surgery, is still denied by most teachers of anatomy the prominence due to its practical importance. This is the more surprising since our knowledge of the subject, as embodied in Sappey's great folio, and in the more recent work of Poirier, Cuneo, and Leaf, is extensive and precise, in spite of the numerous gaps which still exist. Quite recently Professor E. H. Starling's work, The Fluids of the Body, seems to have placed lymphatic physiology on a basis as secure as that occupied by the anatomy of the subject. On the other hand, the problems presented to the surgeon by disease of lymphatic vessels and spaces have, perhaps, hitherto received less than their share of attention. In the evolution of surgery two phases can often be traced, which may be respectively called the ablational and the conservative phases. The rudimentary condition of lymphatic surgery is shown by the almost exclusively ablational methods hitherto employed. Thus, amputation or excision of the diseased tissue have been the methods of choice for lymphatic oedema, while serous effusions are run to waste through a cannula.

The conservative phase of lymphatic surgery is that to which I shall mainly direct your attention. For the aspect of the subject is being changed by the idea of the internal drainage of serous effusions introduced into it by my senior colleagne Dr. Essex Wynter, and by the use of capillary attraction along silk threads as a substitute for destroyed lymphatic vessels in lymplastic oedema, a method which I introduced two years ago.

My material divides itself into three sections: $(a)$ The surgery of lymphatic oedema; (b) the surgery of serous effusions; (c) cancer surgery as a branch of the ablational side of lymphatic surgery. We will first consider the various forms of lymphatic oedema.

\section{Solid Ohdema due to Cancer.}

Dropsy associated with cancer may show itself as a serous effusion in the pleura or peritoneum, or as a local oedema. In the latter form it is most frequently seen in the arm. Less commonly it occurs upon the chest, for, as I have shown, in its early stage cancer en cuirasse is simply a lymphatic oedema of the skin, and no cancerous elements are at first present in the thickened skin. I show you two sections which illustrate this fact.

\section{The Brawny or Dropsical Arm of Breast} Cancer.

A brawny arm develops in 16 per cent. of all cases of breast cancer. Its frequent occurrence depends upon the commencement of the growth in a situation close to the root of the limb, conveniently placed to menace its lines of lymphatic communication. The oedema often commences as a general swelling of the whole limb. In some cases it begins at the wrist and travels upwards; less commonly it begins at the shoulder and travels downwards, or it may first be noticed at the back of the elbow. Sometimes a sharpline of demarcation in the deltoid region separates the swelling from the normal 'tissues above. 'In other cases the shoulder shares in the swelling, which may in a late stage extend to the thoracic wall or to the opposite breast.

Of the 15 cases in which I have done lymphangioplasty in breast cancer, 8 have been on the right and 7 on the left side. Among 54 cases of brawny arm of which, apart from my operative series, I possess notes, 34 have been on the lett side and 20 on the right side. The condition thus appears to be commoner on the left side. Occasionally in association with cuirass cancer both arms are affected.

Dropsical arm is associated with the more chronic forms of breast cancer. In the cases upon which I have operated an average period of six and a half years elapsed between the first sign of cancer and the development of the swollen arm. In one case the swelling took thirteen years to develop, in two others eleven jears. At the opposite end of the scale are two cases in which only six and nine months respectively intervened between the onset of breast cancer and the swelling of the arm. The period of survival which may be expected after a dropsical arm has appeared is difficult to determine, but is not a long one, and probably averages under one year, though in very chronic cases it may exceed three years. Into this short period is usually crowded most of the physical agony caused by the disease. The dropsical arm acquires most of its importance from the excruciating pain which it causes-a pain which in the worst cases almost passes the limits of endurance. This pain is referred to the whole limb, and varies from a dull ache to an intolerable burning agony. It is accompanied by a heavy, leadén drag, due to the weight of the limb. The pain varies in intensity, and there may at first be periods of complete intermission. In several of my cases the pain, though diffuse, has been much worse in the palm of the hand than elsewhere. After a time paralysis of the limb supervenes. The morements of the fingers are the last to be lost. The oedems interferes with passive as well as with active movements of the joints. The elbow is usually held in a position of slight flexion, and can be moved only through a small arc of 30 degrees or less. The wrist and fingers are also stiff, and when the oedema affects the shoulder vertical movements of the scapula upon the chest are prevented. Lastly, the arm may be deeply cyanosed.

\section{Pathology of the Drofsical Arm of Breast} Cancer.

Among the general factors which may contribute towards the appearance of dropsy in cancer is the water.y state of the blood plasma demonstrated by Dr. J. J. Douglas, which acts in two ways-by diminishing transudation and by hindering absorption through the capillary walls. It is also highly probable, though not proven, that toxins which injure the vascular endothelium and thus promote transudation are circulating in the blood.

But the strict localization of the area of oedema in brawny arm shows that local, not general, factors are the chief agents at work. It is a common clinical observation that the drcpsical arm of breast cancer is accompanied by cyanosis and venous congestion of the limb. Hence, the swelling was formerly considered to be caused by venous obstruction, and to result from the pressure of growth upon the axillary veins. Various considerations show the incorrectness of this belief. Thus, Mr. T. W. Nunn showed that the axillary vessels might be completely enveloped in a cancerous mass, and yet the arm might not be swollen. Excision of a length of the axillary veins has not infrequently proved necessary during the removal of a breast cancer, yet in such cases oedema of the am $m$ is rare. In animals obliteration of the main veins of a limb does not produce oedema. The fact appears to be that the venous obstruction in cases of dropsical arm is not the cause of, but is caused by, the dropsy. It has been shown by Professor Starling that if fluid is injected into the subcutaneous tissues of an animal's leg, obstruction or occlusion of the veins may be produced. The rise of [257 I] 
pressure thus produced in the capillaries tends in its tarn to increase the transudation of lymph and to aggravate the dropsy, and thus a vicious circle is set up. The return of the cyanosed limb to its normal colour within a few days of the operation of lymphangioplasty, which I have observed on more than one occasion, is an experimental proof of the truth of the explanation in the cases where this phenomenon is observed. In other cases no doubt the pressure of growth on veins is a minor factor in aggravating the oedema.

If venous obstruction is a consequence of "dropsieal arm," or at most a minor factor in aggravating it, some other explanation of the dropsy must be sought. Mr. T. W. Nunn believed that the oedema was due to obstruction of the axillary lymph. atic trunks by growth within them. But although an obstruction of this kind must be present in an early stage of most cases of breast can. cer, soon after the axillary glands have been attacked by growth, and while the case would still be regarded as operable, at this stage of the disease dropsical arm is never seen. Moreover, the modern operation for breast cancer ruthlessly and habitu. ally divides all the lymphatic trunks during the removal of the axillary glands. Yet after this operation the lymph is easily able to return by collateral routes, and no swelling of the arm occurs. The collateral circulation has presumably been already developed to circumvent cancerous obstruction of the glands.

In point of fact, the onset of a dropsical arm is determined by the blocking, not merely of the main lymphatic trunks, but also of all the collateral routes about the shoulder by which the lymph could find a passage. The pathology of brawny arm is a corollary to the permea. tion theory. As I have shown, permeation spreads from the breast in an everwidening circle, which must ultimately envelop the shoulder completely. I have demon. strated the growing edge of permeation in the deltoid re. gion (Figs. 1 and 2). Perilymphatic fibrosis converts all the permeated lymphatics, small and large, into cords of fibrous tissue, and the arm is entirely cut off from the lymph. atic circulation by the destruction of the lymphatic channels, principal and collateral. Thus, as might be expected, the dropsical arm of breast cancer is not met with until the disease has reached a very advanced stage. Often within a few months of its appearance obstruction to the pleural lymphatics shows itself by the appearance of pleural effusion. What is the factor which determines the collection of serous fluid on the pleura of the affected side? It is the choking up of the subpleural lymphatic plexus by permeation, or its obliteration by consequent perilymphatic fibrosis. Of the former process I am able to show you an excellent photograph. Some time after the arm has been cut off from the lymph circulation the process of permeation, at the opposite side of its circle of extension, reaches the pleura, and, though repeated tapping may give temporary relief, death is certain within a few months at most.

That heart failure done is not the determining factor in the production of bydrothorax is shown by the fact that. out of 28 cases in which pleural fluid was found after death, in 20 the fluid was present only on the same side as the dropsical arm, the other pleara being empty. In 5 cases the fluid was present on both sides; in four of these cases the greater amount of fluid was present on the side of the swollen arm. In 3 cases fluid was present. only on the side opposite to the swollen arm. These figures clearly show that the hydropleura, like the dropsical arm, is a local, not a constitutional, condition. Internal lymphatic obstruction, as indicated by plearal effusion, is present at death in 50 per cent. of cases of dropsical arm. In 34 per cent. of cases no pleural fluid is recorded as present and in 16 per cent. it is de. finitely stated to be absent. But among the 9 cases which come under the latter head. ing 4 showed obliteration of the pleural cavity, or marked pleural adhesions, on one or both sides, so that hydropleura was an impossi. bility. Thas in a majority of chronic cancers which produce brawny arm death is due to internal lymphatic obstruction -a lethal factor the impor. tance of which seems hitherto to have escaped recognition.

\section{Are Bacteria Present in THR Brawny ARM OF Breast Cancer?}

There are certain facts which suggest the possibility of bacterial infection of the tissues as a factor in the production of the swollen arm of breast cancer. M. Doyen in France, Mr. A. Leitch (Director of the Dundee Cancer Research Laboratory), and Messrs. Paine and Morgan in this country, have shown that micrococci are frequently present in cancerous tissues, and the former has given to the organism con. cerned the name of the Micrococcus neoformans. It is probable that this organism has no share in the production of cancer, and that its presence is due to a secondary invasion of the imperfectly vitalized malignant tissues. Such a secondary invasion might conceivably be a cause of obliterative lymphangitis, and of lymphatic oedema. But on two occasions Mr. A. G. R. Foulerton has examined lymph. for me from cases of dropsical arm, and in both instances has found it sterile.

\section{Origin of the Operation} OF LYMPHANGIOPLASTY.

Until two years ago the only treatment available for cases of dropsical arm, after elevation. had ceased to produce any effect, was either amputation of the arm or the use of morphine. The readiness of patients to listen to the suggestion of amputation is the best possible proof of the intolerable agony caused by the disease. Two years ago I was asked to amputate a dropsical arm, the patient's consent to the operation having been obtained. At this time my work in the Cancer Research Laboratories of the Middlesex Hospital had taught me that the condition would be cured if the swollen limb could be provided with a new set of lymphatic vessels. And I bethought me of a section in my possession showing a silk ligature which had been embedded in the tissues for ten years. (Fig. 3). Though superficially eroded, the main sub. stance of the thread is intact. Moreover, the interspaces between the silk fibrils are so small that no intrusive 
cells have been able to enter and obstruct them. The section, moreover, affords no evidence of any clotting of the tissue fluids in the interspaces of the thread. These facts pointed to a silk thread as affording for the tissue fluid a permanent conduit, sufficiently unabsorbable, and not liable to obstruction by organization or thrombosis. I accordingly buried a number - of silk threads in the sub. cutaneous tissues of the arm, and permanently relieved the pain and swelling during the remainder of the patient's life. I mention these facts to show that the operation of lymph. angioplasty was not a casual happy thought, but the endproduct of a long course of laboratory work, which seemed at the time to have no practical application to the treatment of lymphatic obstruction.

Benefits to be Expected FROM LYMPHANGIOPLASTY.

Before describing the operation I wish to state clearly that it is a palliative only, and that it has no claims to prolong life or to modify the natural downward course of the disease. In favourable cases it has the following -effects :

(a) Complete relief from pain within twenty-four hours, unless the pain is partially due to some cause-such as - nerve pressure independent of the oedema.

(b) A marked and rapid fall in the tissue tension of the whole area drained by the threads. The arm in consequence, instead of being hard and brawny, becomes abnormally soft and flabby. This may sometimes occur even though postural treatment is neglected, and in the

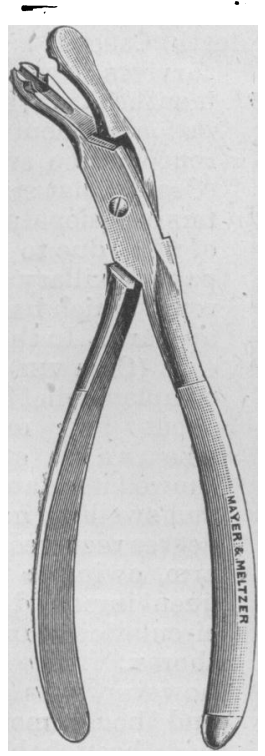

Fig. 4.-Lymphangioplasty forceps, with jaw resigned to grasp either end of the probe firmly and to avoid scratching its surface. of soft metal specially

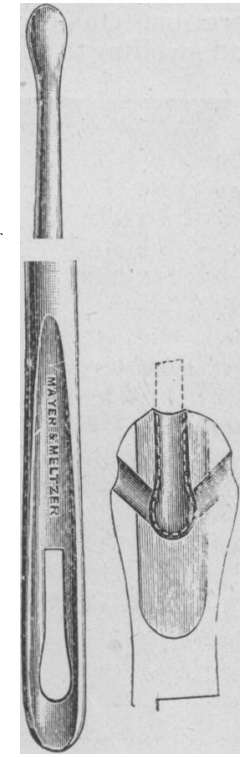

Fig. 5 shows the Iy m pangioplasty forceps, which ar hollowed out in such a way that either end firmly in them. detail of the jaws of

absence of any marked diminution of the diameters of the arm.

(c) Rapid subsidence of the swelling, commencing immediately in the hand, and extending to the forearm within twenty-four hours. At first the upper arm is unaffected, or its diameters may even olightly increase. But within a week or two the diameters of the upper arm are also markedly lessened. The subsidence is usually permanent, unless and until pleural effusion supervenes to interfere with drainage. These effects are at first $d \in p \in n d e n t$ upon the adoption of proper postural after.treatment, but after a fow months elevation of the arm may be entirely abandoned without any marked increase of swelling.

(d) Return of power to the paralysed arm if the para. lysis is of recent date. If the paralysis is of more than a few months' standing, no return of power is to be expected.

(e) An improvement in the general condition, dependent partly upon relief from pain and its associated symptoms of insomnia and depression, and partly upon the abandonment of sedatives.

Teranique of Lymphangio plasty for Brawny Arm.

Tho special materials neces. sary are a set of suitable probes, lymphangioplasty forceps (Figs. 4 and 5), with jaws specially designed to take a firm grip of either end of the probe; and a supply of No. 12 tubular woven silk. These requisites may be obtained from Messrs. Mayer and Meltzer.

The tissues of the arm are drained by two long U-shaped lines of silk, each line composed of two threads of No. 12 tubular silk (Fig. 6). One of these lines drains the front of the arm, the other the back. The bend of each $U$ lies immediately above the wrist, and its two limbs occupy respectively the radial and ulnar side of the limb. Thus, along the whole length of the limb, are found four double lines of silk, spaced out round the limb as nearly as possible at quadrant intervals. Towards the shoulder the lines of silk on the flexor aspect curve outwards around the deltoid muscle, and converge to meet the ascending threads from the posterior aspect at a point near the posterior border of the deltoid. From this point the silk threads again radiate in the subcutaneous tissue of the back, terminating by free ends in the subcutaneous

tissues of $t h e$ scapular region. It is, perhaps. still better to lead some of them to the scapular region of the opposite side, and others to the lumbar region of the same side, - if there is any sign of the oedema ex. tending from the arm to the trunk.

The operation is done as follows

Take a double line of silk, rather more than twice as long as the arm,
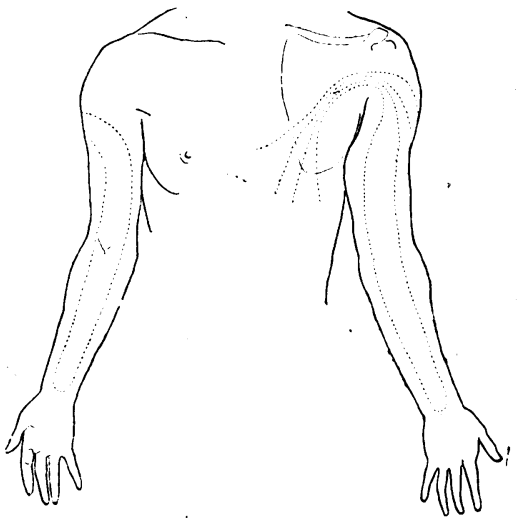

Fig. 6 shows the course of the threads in and mark its mid-point by clipping on it a pair of artery forceps. Wrap up one half its length in gauze. Thread the two free ends of the other half through the eye of a long probe. Make an incision $\frac{1}{2}$ in. long through the skin at the middle of the front of the forearm, just above the wrist.joint. Thrust the probe in the desired line upwards in the subcutaneous tissues well away from the skin towards the region of the elbow, as high as is convenient, and cut down upon its point. Withdraw the probe through the incision last made, and draw the silk after it as far as it will come. Introduce the probe through the incision from which it has just emerged, 
thrust it upwards again in the selected line, and repeat the foregoing steps until the point selected for the convergence of the threads is reached. Here an incision 1 in. long is made, through which the probe with its two silk threads is drawn out. The other half of the silk loop is now led upwards in the selected line along the other border of the flexor surface. The limb is turned over and the extensor loop of silk is similarly introduced. When this has been done eight free ends of silk are hanging out from the incision of convergence at the posterior border of the deltoid. Two at a time these are tucked away in

need to fix the upper ends of the threads by knotting them together, as I formerly thought, for the silk soon becomes ad. herent along its wholelength to the tissues in contact with it.

I will now lay before you my clinical experience of the operation in a series of fifteen cases, analysed into five classes.

\section{A. Cases in which a Dropsical Arm is the Only} Manifestation of Active Disease.

Three of the cases in my series may be regarded as ideal ones for the operation of lymphangioplasty. Each of these had a long history of cancer, the disease baving

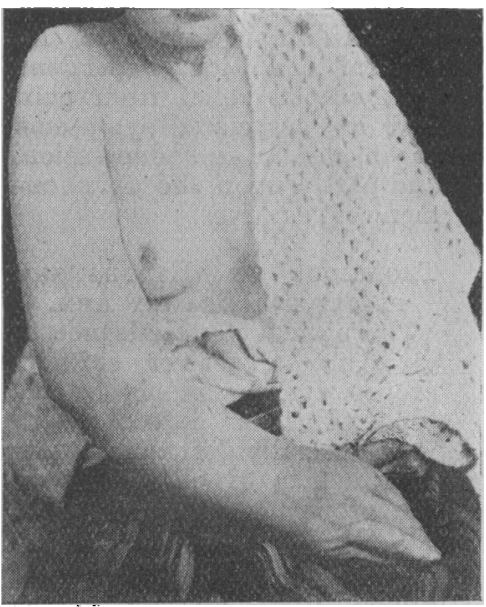

Fig. 7.-Cage I before operation.

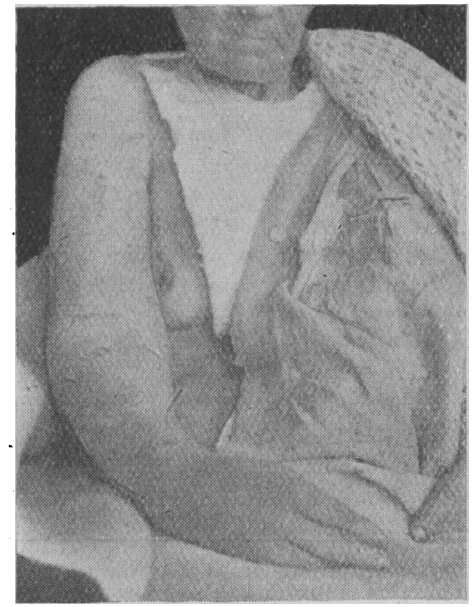

Fig. 8.-Case I shortly after operation. various directions in the subcutaneous tissues of the back by the following mancuvre.

Clip a forceps on the selected pair of silk threads just where it emerges from the topmost incision. Take a long probe, cut off the ends of the two threads so that they are 4 in. shorter than the probe, and thread them into the eye. Thrust the probe downwards from the incision in the desired direction until the probe unthreads itself. With. draw the probe carefully, leaving the two silk threads to occupy its track. When all the threads have thus been tucked away, the operation is completed by sewing up the incisions with horsehair.

The principal diff. culties of the opera. tion are connected with the maintenance of the silk in an aseptic condition. Owing to the large area dealt with, extending on to the back, the necessary changes in the posture of the arm, and the length of the silk threads, accidental contact may very easily occur between the silk and the surface of the skin, the edges of the incisions or surrounding objects. I regard the use of masks as essen. tial, and the silk ends not actually dealt with

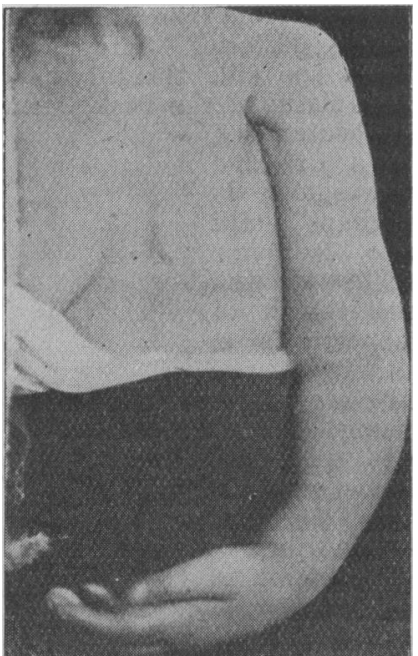

Fig. 10.-Crser'II before*operation.

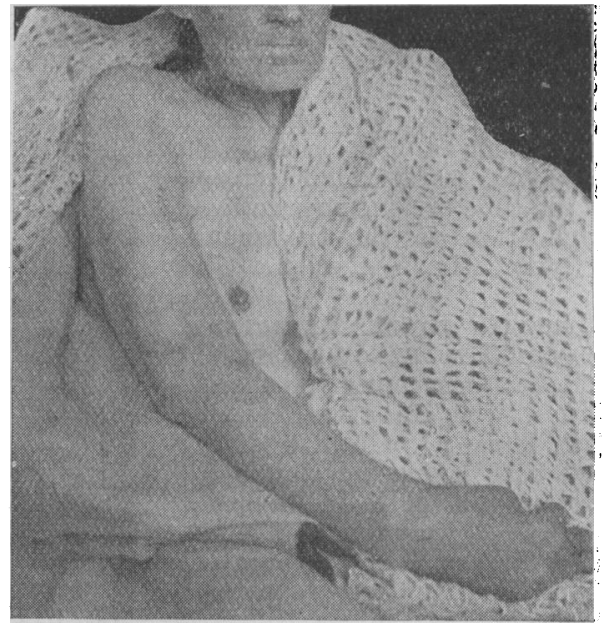
Fig. 9.-Another view of Case r after operation. began respectively fourteen, fourteen, and seven years previously. Evidently, the defensive processes of fibrosis were exceptionally active. In each of these cases no clinically discoverable mass of cancer existed at the time of the operation, and no ulceration was present as a menace to operative asepsis. Under these conditions the operation appears to be uniformly successful. In all these cases. pain and swelling were relieved within a day or two of the operation. One of them (Figs. 7-9) remained free from pain and swelling to the day of her death (Case I), $\because$ a second

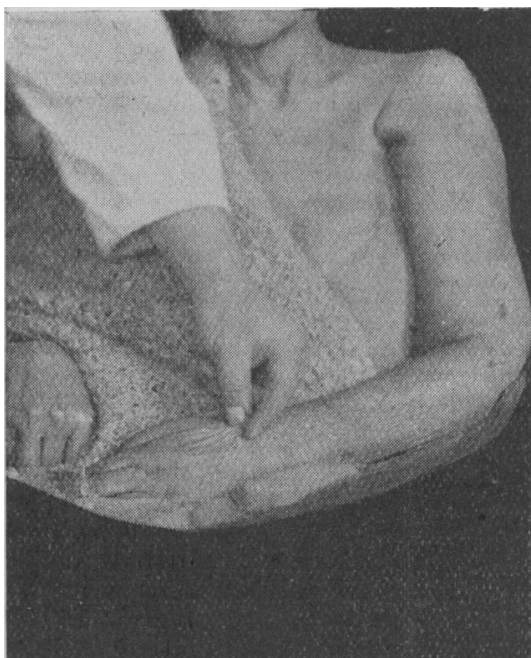

Fig. 11.-Case; II after operation. Note the considerable flexion of the elbow which
is now possible, and the laxity of the skin. survives twenty-one months after the operation without recur. rence of the swelling (Case v), but still suffers occasional attacks of pain, due to a palpable axillary recurrence which has now appeared. In the third case (Case viri), after complete relief lasting about four months, pleural effusion showed itselfand pain and swelling in some degree recurred in the arm, owing to consequent impaired lymph circulation in the thorax. The pain, however, was slight, and though morphine had been habitually used prior to the operation, it remained unnecessary until the pationt's death from pleural effusion and thoracic growth.

B. Cases in which Recurrent Masses of Growth are Present, but Ulceration and Pleural Effusion are Absent.

Six of my cases come under this hoading, and may thus be summarized :

CASE Ir.-Inoperable recurrences in the axilla, near the scar, and in the right eye. Complete relief of swelling, and considerable relief of pain, persisting till death from internal deposits. (Figs, 10 and 11.) 
CASE IV:-Enlargement of the left supraclavicular glands. Some relief at first, but a rapid relapse, associated with excessive use of the arm and neglect of after-treatment.

CASE VI.-Enlarged glands in the axilla, and tbickening adjacent to operation scar. Great relief. Death three months later from advance of the disease. (Fig. 12.)

CASE IX.-Enlarged glands in both supraclavicular regions. Pain chiefly located in the axilla. No relief. Nodular recurrence in the scapular region along the lines of silk.

CASE X.-Recurrence present in the subclavian glands. Pain of a stabbing or shooting character. No relief.

CASE XIr.-Enlargement of right supraclavicular glands and suspicious induration along the coraco-brachialis. A small nodule near the scar. Partial relief, slowly increasing to almost complete relief.

In all of these cases recurrent masses of growth were present in the neighbourhood of the brachial plexus. Three of these were successful; in one the period of benefit was very short, and two were failures.

In this class of case the difficulty is to decide how much of the pain is due to nerve pressure and how much to the dropsical arm. Evidently, in view of the successful cases, the mere presence of growth in the axilla or supra. clavicular region is not a bar to operation, but the relief obtained may not be com. plete, and in half the cases no benefit results. My experi. ence teaches that if the pain is referred mainly to the axilla or supraclavicular region, or if it is a lancinating pain shooting down the arm, little or no benefit is to be expected from lymphangioplasty.

If, on the contrary, the pain is a heavy diffuse pain referred to the whole limb, or if it is located in the elbow or the hand, the operation will afford relief, even though there is recurrence above or below the clavicle.

C. Cases in which Axillary or Thoracic Ulceration is Present, and Pleural Effu. sion is Absent.
Fig. 12.-The arm in Case vi before and shortly after

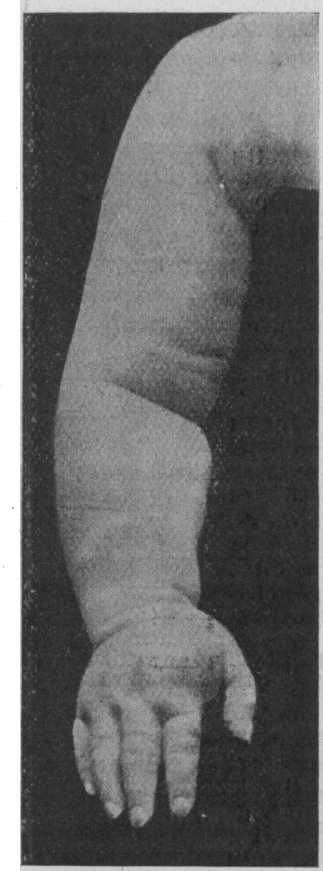

CASE VII.-Extensive ulceration of the chest and axilla with scattered nodules of growth. Normal convalescence and primary union after lymphangioplasty, with relief from pain and subsidence of swelling. Three weeks after operation intercurrent acute eczema attacked the arm, and pain and swelling recurred.

CASE XI-Fczematous and crusted area on the left side of the chest, with axillary ulceration; excruciating pain, chiefly referred to the palm of the hand; lymphangioplasty; primary union. Complete relief from this pain and from brawny swelling of the arm until her death from pleuritic effusion and thoracic metastases. The swelling of the apper arm recurred when the chest filled up but did not again become hard and brawny.

CASE xv.-Brawny arm, acute pain, and paralysis of arm. Deep axillary ulceration wrapping round the arm, but leaving a bridge 6 in. wide posteriorly. Profuse suppuration from the ulcer. Acetone treatment. Lymphangioplasty. Primary union. Most marked relief of pain and swelling, and return of muscular power, so that the patient was able to write me a letter of thanks with the hand which had been completely paralysed.

The onset of acute eczema of the arm three weeks after operation in Case vII is a complication unique in my experience, and may fairly be regarded as an unfortunate accident which spoiled a case giving every promise of success. I may remind you that when physiologists wish to increase the production of lymph in a limb, the method they adopt is to scald the skin of the anaesthetized animal. It is easy to believe that acute eczema would have a similar effect. The other two cases in this class were unequivocal successes. It may, I think, be concluded that the presence of ulceration does not apprecisbly increase the risk of lymphangioplasty, provided means are taken to clean the ulcers and to shut them off effectually from the field of operation. With my present experience I should not hesitats to operate upon cases such as the following.

In October, 1908, I saw at Selkirk, with her medical attendant Dr. J. S. Muir, a lady with the following history:

The right breast had been removed for cancer seven years the operation. a cancerous ulcer npon the thorax or in the axilla, it would be very difficult to prevent contamination of the silk threads.

The first case (Case vir) upon which I operated in the presence of ulcerated growth was submitted for a month previously to ionic medication with mercury in order to cleanse the ulcers. In subsequent cases, antiseptic irrigations, and lately applications of acetone, have been employed.

Thanks to the loyal co-operation of medical and nursing colleagues in these and other precautionary measures, the calamity of suppuration has never occurred. In every case all the incisions have healed by primary union, nor has it been ever necessary in any of the cases under this heading to remove the threads. Repeated success in these cases has increased my boldness in dealing with them. In my latest case (Case XV) the axilla was a gaping chasm pouring out pus, and the ulceration had completely surrounded the arm save for a bridge of normal tissue posteriorly, about 6 in. wide, which afforded the only possible avenue for the threads. In this case primary union of the incisions occurred, and the patient is delighted with the relief of pain and swelling, and the return of muscular power which have resulted from the operation. Dr. A. O. English acted as house-surgeon, and the case may be seen in Stafford Ward, one of the cancer wards of the Middlesex Hospital.

The cases in this class may be briefly summarized:

previously by Professor Caird. A year later the same surgeon excised some cancerous nodules near the cicatrix. Others made their appearance, and were treated with $x$ rays by Dr. Dawson Turner with decided benefit. But an intractable ulcer remained, which was two years in healing. Meantime the disease recurred in the surrounding region, involving a large area of gkin on the side of the thorax, from the axilla to the ninth rib. skin on the side of the thorax, from the axing to the ning movement at the shoulder. The arm is swollen from the apex of the ment at the shoulder. The arm is swollen from the apex of the deltoid down to the wrist. The extensor muscles of the hand and fingers are atrophied, the latter being flexed. The patient plains far more of this than of the malignant ulceration. Her internal organs appear. sound, and her general health good, in spite of sleepless nights and the occasional use of opiates-a spite of sleepless nights and the occasional use of opiate

In this case, though the patient was perfectly prepared for operation, I told her that the large ulcerated area on the chest added considerably to the risk, and she decided to defer it. Elevation on a splint was subsequently tried without benefit.

With my present experience I should feel justified in stating in a similar case that the extra risk involved is very small, and should definitely advise operation.

D. Cases in which Pleural Fluid or other Evidence of

Thoracic Cancer is Present, but the Condition of the Patient does not Negative a General Anaesthetic.

When pleural fluid is present the balance of life remain. ing to the patient is in any case likely to be a short one. Thus in one case the chest only filled up two days before 
death, and $70 \mathrm{oz}$. of fluid were present in the pleura on the affected side. This is an extreme case. As a rule pleural effusion precedes death by two or three months, occasionally perhaps by a year. Apart from this question of survival, the success of the operation is doubtful, for hydrothorax shows that the lymphatic block extends over a wide area including the pleura. Under such conditions nothing can be promised, but if paracentesis is also done a few weeks' relief may be obtained, and therefore an urgent desire on the patient's part for a brief respite from pain may justify an operation. The necessity of morphine -a drug to which many people have a kind of conscientious objection-may thus be postponed for a while.

CASE XIII.-Recurrent mammary cancer with dropsical arm and very severe pain. Pleural effusion. Paracentesis followed by lymphangioplasty. Marked relief of pain and swelling. Recurrent hydrothorax for which several tap. pings were necessary, and death from advancing disease in the thorax within five weeks. Swelling did not recur in the arm, but oedema appeared in the axilla and extended across the chest to the left breast. The relitf obtained during the short remainder of life was masked.

Case XIV.-Re-

curent nlcer-

ated mammary

cancer with

dropsical arm.

Impaired $r \in s o$. nance at the

base on the same side. The patient's suffer. ings were so great and her dislike of morphine so strong, that she ur. gently asked for operation, "even if the relief lasted only threi days." Lymphangioplasty. $R$ a pid s ub. sidence of swelling and com. plete freedom from pain for ten days, when recurrence of pain and swelling coincided with the development of hydrothorax.

E. Cases in which the Patient is so Ill that the Risk of a General Anaesthetic cannot be faced, or in which the Silk Threads must be led through Cancerous Tissue.

Assuming the white sheet of penitence, I must now relate to you the remaining case of my operation series (Figs. 13 and 14), which embodied both of these absolute contraindications to the operation of lymphangioplasty. This case (Case III), one of my earliest, was in an almost moribund condition with thoracic cancer and pleural $\epsilon$ ffusion, and was suffering tortures from a dropsical arm. A general anaesthetic seemed out of the question. Under a local anaestbetic an attempt was made to ease her last days by a rapid partial lymphangioplasty, using a single line of narrow silk ribbon instead of thread. But such pain was caused by the passage of the probe through the subcutaneous tissues above the okin incision that a general anaesthetic had to be given. At the shoulder the ribbon passed through an indurated area of diffuse subcutaneous cancer. No relief followed, and suppuration occurred along the line of the silk. She died about a week later. If the operation shortened her life, it was by a few days at most. I claim for this case the indulgence due to a pioneer mistake.

Mortality of Lymphangioplasty for Breast Cancr

The case which I bave just described is the only one of my series in which primary union has failed, and the only one in which death has followed closely upon the operation. Including this unsuitable case, the operation mortality of my series is 7 per cent.; excluding it, the operation reortality is nil. ' I think an impartial critic will agree that the latter is the fairer estimate, and that my cases show the procedure to be almost free from risk to life when asepsis is maintained. The operation is indeed equivalent merely to a 5 -jnch skin incision, that being about the aggregate length of the multiple small incisions. Shock and haemorrhage need not be feared. The cradle-splint. represented in Fig. 15 will be found very useful during: convalescence. It was suggested to me by Dr. J. M. Brydone.

Rrmoval of the Silk used in Lympeangioplasty.

The following are the cases in which $I$ have had to remove silk inserte $d$ for lymphatic drainage.

1. L. D. Lymphangioplasty for brawny arm of breast. cancer. Primary union. The patient was discharged with. the incisions soundly healed. Several montbs later she was admitted with suppuration extending along one of the. threads from the wrist to the elbow. The corresponding incisions had reopened. She bad neglected after-treatment, and, as she lived alone, she had used the arm for rough and dirty housework.

The infected length of silk was cut through by subcutaneous tenotomy well above and well below the limit of infection, and was easily withdrawn through one of the reopened incisions. The tract was syringed out with zinc chloride, 10 grains to the ounce. The incisions closed within a fow days afterwards. 2. A case of elephantiasis to be described in Lecture II.

The Choice of CASES FOR LYMP HANGIO PLASTY.

The preceding analysis of my cases shows that l g m pangioplasty is contraindicated in cases where a general anaesthetic cannot. be borne, and in cases where the silk threads would have to pass through cancerous tissue. It is also inadvisable to operate where there is growth present about the shoulder, if the pain is mainly an axillary one, or is a lancinating pain shooting down the arm. In the presence of pleural effusion or secondary growths the benefits of the operation are transient, but the shortest period of relief may, under the circumstances, be considered by the patient as worth baving.

Minor Degrees of Swelling.

Minor degrees of obstruction to the return of lymph. from the arm are not infrequently met with in breast cancer. The operation of lymphangioplasty should not be applied indiscriminately, but should be reserved for the severer degrees of lymph.stasis in which other modes of treatment are powerless.

The axillary scarring which necessarily follows removal of glands may sometimes lead to persistent oedema of the arm, usually slight in amount. In such cases the application of a bandage and the elevation of the arm on an inclined plane for one or two hours a day will usually suffice. In other cases, which ultimately develop into the true brawny arm, the lymph obstruction is partial only. In such cases, although the arm may attain a very con. ciderable size, the oedema is soft, and pits freely on pressure. Postural treatment by elevation will sometimes in this stage reduce the size of the arm considerably, and will, to some extent, relieve the pain. The necessity of operation is thus for a time deferred, but the relief obtained is not to be compared with that resulting from lymphangioplasty. It appears, moreover, to be very transient, and in many cases even before the oedema. has 
become solid, postural treatment is intolerable because it severely aggravates the pain. This fact is easily explicsble, since the lymph from the forearm, flowing easily upwards into the arm and meeting obstruction there, distends the tissues of the upper arm to an unbearable

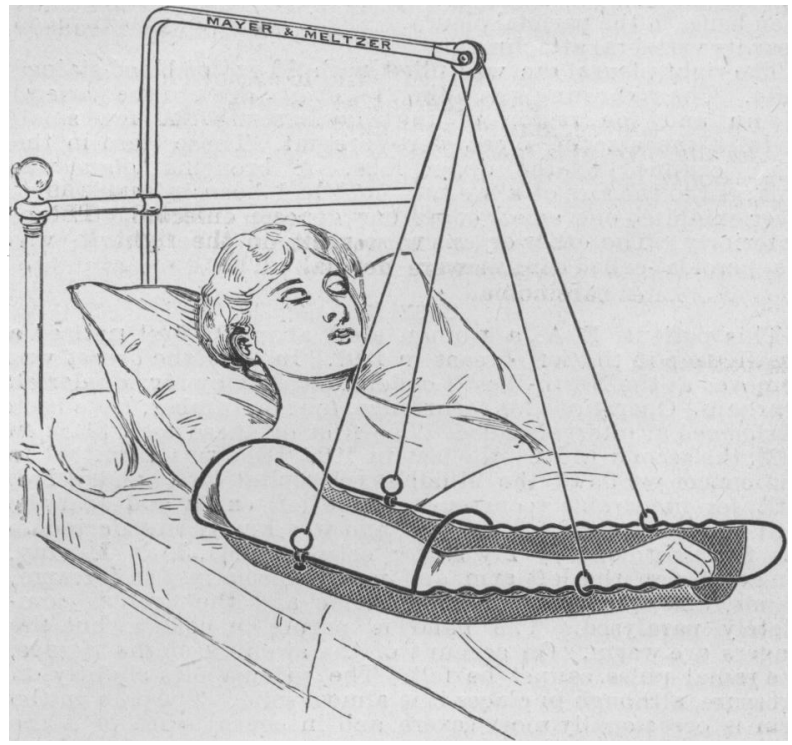

Fig. 15.-Cradle-splint for use after lymphangioplasty.

extent. In the following case the effects of postural treatment are seen at their maximum.

CASE E. E.-A woman, aged about 60 , was admitted into the cancer wards of the Middlesex Hospital at the beginning of August, 1908. She suffered from recurrent breast cancer of the August, 1908. She suffered from recurrent breast cancer of the but it pitted freely on pressure. She was ordered to have the .arm elevated on an inclined plane at an angle of about 25 degrees with the horizontal for two hours daily, but, owing to the painful tension produced in the scar tissue of the axilla, she could not bear the elevation for more than one hour daily. Tho swelling of the forearm at first subsided rapidly, while the tpper arm later showed slight improvement. Within a month, however, most of the improvement had been lost. She declined operation. The following are the messurements of the arm:

\begin{tabular}{|c|c|c|c|c|c|}
\hline & & Aug. 7th. & Aug. 10th. & Aug. 14th. & Sept. 4th. \\
\hline Round hand $\quad \ldots$ & ... & in. $_{8}$ & $\operatorname{in}_{6 !}^{3}$ & $\operatorname{in}_{6}^{5}$ & $\operatorname{in}_{7+}$ \\
\hline At wrist $\quad \ldots \quad \ldots$ & $\ldots$ & $6 \frac{3}{4}$ & 64 & $6_{s}^{1}$ & $6 \frac{3}{4}$ \\
\hline $4 \frac{1}{2}$ in. above wrist & ... & $10 \frac{3}{4}$ & $8 \frac{1}{4}$. & 9 & 10 \\
\hline At elbow $\ldots \quad \ldots$ & ... & $14 \frac{1}{4}$ & $14 \frac{1}{4}$ & $12 \frac{3}{4}$ & $13 \frac{1}{2}$ \\
\hline$d_{\frac{1}{2}}$ in. above elbow & ... & $13 \frac{1}{4}$ & $13 \frac{1}{2}$ & $12 \frac{3}{4}$ & $13 \frac{1}{4}$ \\
\hline 4 in. above elbow & ... & 11 & 121 & $9 \frac{1}{4}$ & 14 \\
\hline
\end{tabular}

Thus, even in favourable cases, where the affection has not reached the stage of brawny hardness, the effects of posture are temporary and imperfect. If the oedema is marked and progressive, and if postural treatment is painful or ceases to be effective, the stage of brawny hardness should be anticipated and prevented by the per formance of lymphangioplasty. The only objection to this course is that the patient will underestimate the benefits she has derived from the operation, for prophylaxis is less striking than cure, and earns less gratitude.

The following case is an instance of the mild post-operative oedema for which lymphangioplasty is unnecessary :

B. F. S., aged 35, was operated upon by me for breast cancer three years ago. She remains (January, 1910) free from any sign of recurrence, but three months after the operation some oedema of the right arm and hand, extending upwards nearly to the elbow, began to show itself, and has since persisted. The upper arm remains comparatively free from swelling. The oedema pits on pressure. Elevation rapidly reduced it as shown in the following table, and no operation was advised. In shown in the following table, and no operation was advised. In splint whose upper end is slung to the head of the bed, an arrangement which in no way disturbs her rest. During the day she is to use the arm as usual.

\begin{tabular}{|c|c|c|c|c|c|c|c|}
\hline & & & & & & Jan. 12th. & Jan. 24th. \\
\hline Round the han & & $\ldots$ & $\ldots$ & $\ldots$ & $\ldots$ & in. $_{9}$ & ${ }_{8}^{\text {in. }}$ \\
\hline At wrist ... & $\ldots$ & $\ldots$ & $\ldots$ & $\ldots$ & $\ldots$ & $8 \frac{1}{4}$ & $7 \frac{1}{4}$ \\
\hline Below elbow & $\ldots$ & $\ldots$ & ... & ... & ... & 10 & $9 \frac{1}{2}$ \\
\hline Above elbow & $\ldots$ & $\ldots$ & $\ldots$ & $\ldots$ & ... & $10 \frac{1}{2}$ & 9 \\
\hline
\end{tabular}

In this case there is evidently no true blockage of the lymph stream, but only a slight insufficiency in the total calibre of the lymph channels, owing to the interference produced by the operation. In such cases lymphangioplasty is usually unnecessary.

Erysipelas as a Cause of Lymphatic Oedema.

Lymphatic oedema sometimes, though rarely, supervenes on eryeipelas in situations where the subcutaneous tissues are loose and easily distended by serous fluid. Its most common sitnation is the eyelids, though it may affect more or less the whole of the face. In such cases it is easy to imagine, though impossible to prove, that the lymphatic vessels of the part have been obliterated by an unusually eevere lymphangitis which has swept tbrough them like a prairie fire, leaving only fibrous cords to represent the vessels.

No satisfactory treatment has hitherto existed for Jymphatic oedema of the eyelids following erysipelas, and I was very anxious for an opportunity to try the effect of lymphangioplasty in such a case. The method I had intended to try was as follows:

Make a small horizontal incision $\frac{1}{4}$ inch long just outside the outer canthus. Take a suitably curved, fine, sharp.ended probe loaded with No. 8 tubular silk, and pass it from the incision through the thickened subcutaneous tissue of the eyelid parallel to and just below its free edge to the inner canthus. Here the skin is pierced from within by the point of the probe. The probe is completely pulled through, and the end of the silk follows it out through the puncture. The other end of the silk is now threaded through the probe, and its sharp end is pushed from the incision downward through the subcutaneous tissues of the cheek over the parotid gland for about $1 \frac{1}{2}$ in. The point of the probe is here made to emerge through the skin, and the probe, carrying with it the end of the silk, is withdrawn and unthreaded. In a similar fashion another thread is placed in position in the lower eyelid lying below the first but emerging at the same points on the skin. The upper ejelid is now dealt with in exactly the same way, its threads entering at the same incision, and emerging at punctures closely adjoining those from which the threads of the lower lid emerge. The ends of the threads are now all shaved off close to the skin, through the thickness of which they are caused to retract by a gentle pull applied to each thread where it lies in the floor of the incision. The incision is now sewn up with a point or two of horsehair, leaving the threads in position as four parallel lines, two in each eyelid, with their outer ends prolonged downwards into the subcutaneous tissue of the cheek.

In the absence of a suitable case I have been unable to try this method of operation. Priority in the application of lymphangioplasty to this class of case belongs to $\mathrm{Mr}$ A. B. Mitchell of Belfast, who in two successful cases used a method differing only in technical detail from the one I intended to employ.

CASE r.-(Mitchell). A man, aged 25, had facial erysipelas in June, 1907. Solid oedema of the ejelids resulted, upon which treatment, inclading injections of flbrolysin, had no effect. Four threads were introduced in June, 1909, one in each eyelid on both sides of the face. Great improvement resulted within three weeks. One thread caused slight irritation, and had subsequently to be removed. The others still remain in position.

CASE II.-(Mitchell).* A young soldier in 1907 suffered from eryeipelas of the left side of the face following an operation upon the cervical glands. Solid oedema of the face and lips supervened, and persisted until May, 1909, when Mr. Mitchell introduced $t w()$ silk threads leading from the subcutaneous tissues over the masseter muscle downwards to the loose tissue

*A. B. Mitchell. A Case of Lymphangioplasty for Solid Oedema. British MEdical JodrnaL, November 20th, 1909. 
behind the clavicle. The result . Was entirely satisfactory. The threads never gave the slightest trouble, and the face assumed its natural contour.

I am much indebted to Mr. A. B. Mitchell for supplying this conclusive evidence of the value of lymphangioplasty in post-erysipelatous oedema. These cases supply an additional proof, if one were needed, that the effects of lymphangioplasty in the limbs are not primarily due to the elevation which forms a necessary part of the aftertreatment. The eyelids tend to drain by gravity either into the face or the scalp whether the patient be standing or lying. Yet until the operation, in.each of Mr. Mitchell's cases the oedema had persisted unchanged for about two years.

\section{Appendix of Cases.}

Case I.

The patient, a woman aged 56, was admitted into the cancer wards of the Middlesex Hospital on January 18th, 1908, under my senior colleague Mr. J. Bland-Sutton, who kindly trans ferred her to me for treatment. In 1894 a portion of the right breast was removed for carcinoma at the Chichester Hospital. In 1896 recurrences in the breast and axilla were removed at St. Mary's Hospital. In 1903 two or three small recurrent growths were removed from the axilla. In 1905 the right arm became swollen; it slowly became paralysed, and has been the seat during the past three years of excruciating pain, which frequently kept her avake at night. On admission, there was no evidence of cancer in the body in the form of palpable indrawn, and there was no lump in what remsined of the right breast, nor was there any axillary mass of growth. The chest and abdomen were free from deposits. The growth was evidently an atrophic scirrhus, which had undergone an almost omplete process of natural cure. The right hand and arm below the deltoid insertion was greatly swollen. The oedems pitted slightly on pressure, though it approsched the solid variety. There was complete paralysis of the limb, aave that the third and fourth fingers moved slightly. Sensation was lost in the thumb and first finger, bnt not in the second, third, and fourth. The hand was warm and of natural colour. Flexion of the elbow was only possible through i5 degrees, or rather less. On February 1st, 1908, lymphangioplasty was performed. The operation produced no general disturbance of note. On the next day it was obvious that the bandages were loose, and the strapping upon her fingers was in the same condition and had to be frequently replaced. On February 6th it was noted that the arm and hand were gnite flabby and much reduced in size. The skin was much wrinkled, and hung awkwardly on the fingers in folds. On February 7 th the patient remarked movements of the fingers were beginning to return, and she was able to grasp very feebly. The arm was still quite paraly sed. On February 10th the forearm and hand began to present an almost normal appearance, but much swelling of the upper arm remained. On February 19th the swelling about the elbow which as the patient lay was the lowest point of the limb, had somewhat increased, and the limb was ordered to be pat up on an inclined plane in an extended position and to be bandaged during the night. On February 24th the limb was continuing to diminish in size, though less rapidly then at first. Unfortunately messurements of the limb previously to operation were omitted, so that no accurate record remains of its very rapid and marked subsidence in the earliest days after the operation (Figs. 7, 8, and 9). Its slower subsequent subsidence is recorded in the following table.

Circumference of Arm.

\begin{tabular}{|c|c|c|c|c|c|c|c|c|}
\hline & & $\begin{array}{l}\text { Feb. } \\
\text { 6th. }\end{array}$ & $\begin{array}{l}\text { Feb. } \\
\text { 13th. }\end{array}$ & $\begin{array}{l}\text { Feb. } \\
\text { 18th. }\end{array}$ & $\begin{array}{l}\text { Feb. } \\
\text { 19th. }\end{array}$ & $\begin{array}{l}\text { Feb. } \\
\text { 2lst. }\end{array}$ & $\begin{array}{l}\text { Feb. } \\
24 \text { th. }\end{array}$ & \\
\hline At wrist & ... & in. & $i_{6 \frac{7}{6}}$ & in. & in. & in. & in. & \\
\hline $4 \frac{1}{2}$ in. above wrist $\ldots$ & ... & 83 & $8 \frac{1}{8}$ & $8 \frac{1}{4}$ & 8 & 78 & 78 & \\
\hline Just below elbow ... & ... & $1 C_{\frac{1}{2}}^{\frac{1}{2}}$ & $9 \frac{1}{2}$ & $100^{*} *$ & $10 \frac{1}{8}$ & $9 \frac{9}{8}$ & $9 \frac{5}{8}$ & \\
\hline in. above acromion & ... & 11 & $8 \frac{7}{8}$ & $10 \frac{1}{2} *$ & $10 \frac{3}{8}$ & $9 \frac{1}{2}$ & $9 \frac{9}{8}$ & \\
\hline
\end{tabular}

* Temporary return of swelling owing to dependent position of elbow. Note.-The operation was performed on February lst.

On April 8th it is noted that the patient has lost her pain, and that she is very grateful for the operation. Flexion of the elbow is now possible through about 110 degrees, as compared with about 15 degrees or less before the operation. The movements of the hand continued to improve so that the patient could hold $a$ pin between the finger and thumb, but no return of power took place in the muscles of the arm. She developed signs of a took place in the muscles of the arm. She developed signs of a deposit of cancer in the left great trechanter, and died
June 10th without recurrence of the swelling in the arm.

Abstract of Necropsy.

Upon the right arm and in the right pectoral region some fine longitudinal scars were seen. Two incisions were made in the limb, and thence $3 \mathrm{in}$. or $4 \mathrm{in}$. of silk were extracted.
The silk had undergone hardly any change, and maintained its continuity along the limb. It had become firmly attached to the subcutaneous tissue which lay in contact with it. The right breast had been only partially removed. A mags of new growth, about 2 in. by 1 in., was present beneath the breast tissues, mainly between the ribs and parietal pleura, and besides this larger mass a number of small nod vles could be seen beneath the parietal pleura. The fourth rib was invaded near its vertebral attachment

The right pleural sac was flled with $16 \mathrm{oz}$. of blood-stained fluid. The right lung was adherent at its apex to the parietal pleura and the region of the new growth. A few small nodules the size of a pea were present. These were in the main confined to the upper lobe. A bronchial gland was enlarged to the size of a walnut, and had been infected. The liver exhibited one small subserous deposit on the right lobe anteriorly. The other organs were normal. The growth was a spheroidal-celled carcinoma.

CASE II.

This patient, E. A., a woman aged about 50, first noticed a small lump in the left breast in 1897. In 1899 the breast was removed at the North-West London Hospital by Mr. Frederick Durham. Operations for recurrence, four in number, have been performed at intervals since. The first of these took place in the cancer wards of the Middlesex Hospital on January 3rd, 1908 , for inoperable recurrence in the left axilla and near the scar and for swelling of the arm, and was kindly transferred to me for treatment by my senior colleague, Mr. John Murray. On admission the left arm, and more especially the forearm, hands, and fingers are much swollen, and the limb is completely paralysed. The hand is purple in colour, but the fingers are warm. On account of the swelling of the tissues the radial pulae cannot be felt. The oedema pits slightly on pressure, although in places it is almost solid. The pain in the arm is occasionally most severe, and in consequence of it the patient suffers much from insomnia. Amputation had been suggested before the patient's admission, and her condition was so miserable that she was prepared to welcome the loss of the limb.

Owing to the axillary recurrence and the consequent absence of loose skin on the thoracio wall in front, it was deemed well in this case to carry the threads up on the posterior aspect of the axilla, and this has since been my rontine practice. They terminated in the subcutaneous tissue over the scapula. Four pairs of threads were used, as in the previous case-two on the flexor and two on the extensor aspect of the arm.

Measurement of Arms.

\begin{tabular}{|c|c|c|c|c|c|c|}
\hline & \multirow{2}{*}{$\begin{array}{l}\text { Right } \\
\text { Arm } \\
\text { (nor- } \\
\text { mal.) }\end{array}$} & \multicolumn{5}{|c|}{ Left Arm. } \\
\hline & & $\begin{array}{c}\text { Before } \\
\text { Opera- } \\
\text { tion. }\end{array}$ & $\underset{\text { 3rd. }}{\text { March }}$ & $\begin{array}{l}\text { March } \\
\text { 13th. }\end{array}$ & $\begin{array}{l}\text { March } \\
\text { 18th. }\end{array}$ & $\begin{array}{l}\text { April } \\
6 \mathrm{th} .\end{array}$ \\
\hline $4 \frac{1}{2}$ in. above wrist $\quad \ldots$ & in. & $\operatorname{in}_{9 \frac{1}{4}}$ & in. & $\operatorname{in}_{67}$ & in. & in. \\
\hline Just below elbow & $8 \frac{3}{4}$ & $111 \frac{1}{4}$ & $9 \frac{3}{8}$ & $8 \frac{7}{8}$ & $9 \frac{3}{8}$ & 9 \\
\hline $1 \frac{1}{2}$ in. above elbow $\quad \ldots$ & $8 \frac{3}{4}$ & $12 \frac{1}{2}$ & 10 & 97 & $10 \div$ & 10 \\
\hline 8 in. below acromion... & 9 & 12 & $10 \frac{1}{8}$ & $10 \frac{3}{8}$ & 9 案 & $9 \frac{2}{4}$ \\
\hline $\begin{array}{l}\text { Just below fold of } \\
\text { axilla }\end{array}$ & 10 & $10 \frac{3}{4}$ & $11 \frac{1}{2}$ & $11 \frac{1}{2}$ & 11 & $10 \frac{8}{8}$ \\
\hline
\end{tabular}

The swelling in this case, as in Case I, subsided from below upwards, the subsidence being first noticed in the hand and forearm (Figs, 10 and 11). The excruciating pain has been entirely relieved, and the patient has good nights. She appears to be putting on flesh, and her worn expression has been to be putting on flesh, and her worn expression has been amount of axillary pain, due to the recurrent growth in the axilla.

After about two months postural treatment was abandoned, without return of the swelling in the arm and hand. Subsequently she had considerable pain from secondary deposits in the right eye, and in the autumn her condition rapidly changed for the worse, although no swelling returned in the arm. In November there was slight increase in the diameters of the hand and arm, but with no return of the brawny hardness, and she died of secondary deposits on December 5th.

At the necropsy a secondary deposit was found at the back of the orbit, extending into the cranial cavity. The sternum was partly replaced by new growth. The left humerus was fractured at about the juncture of the middle and lower thirds. No other secondary deposits were found, and there was no fluid in the pleural cavity.

CASE III.

This case has already been described in the lecture (Figs. 13 and 14).

Miss D., aged 68, had her left breast removed for carcinoms at the London Hospital in 1901 or 1902. The growth had been present for three years. Two years after the opera. tion a secondary nodule was excised from the scar. In 19:0 another secondary nodule was excised. About April, 1906; she 
noticed that her left hand was beginning to swell, and the swelling has gradually extended up the arm. It has caused great pain, and in consequence of it she has had very sleepless nights. She has, however, been able to use her arm until quite lately. Tingling in the fingers has been a marked symptom.

On examination the scar of the operation is sound. No secondary nodules are preserft, nor could any glands be felt in the axilla, though there appears to be enlargement of the left supraclavicular glands. The left arm is swollen from the middle phalangeal joint to just below the tip of the acromion process, where there is a well-marked line of demarcation. The patient has free movement of her arm, and is able to move her fingers.

On April 18th, 1908, lymphangioplasty was done in the usual manner, except that an additional length of silk was better to drain this region.

On April 20th an obvious decrease in the size of the arm was noted and the improvement was continuous. The wounds healed, and dressings were left off on April 30th. She left the hospital on May 5th, somewhat relieved.

Measurements of Arms.

\begin{tabular}{|c|c|c|c|c|c|c|}
\hline \multirow{2}{*}{\multicolumn{2}{|c|}{ ( }} & \multicolumn{4}{|c|}{ Left Arm. } & \multirow{2}{*}{$\begin{array}{c}\text { Right } \\
\text { Arm } \\
\text { (normal). }\end{array}$} \\
\hline & & $\begin{array}{l}\text { April } \\
16 \text { th. }\end{array}$ & $\begin{array}{l}\text { April } \\
\text { 23rd. }\end{array}$ & $\begin{array}{l}\text { April } \\
\text { 27th. }\end{array}$ & $\begin{array}{l}\text { May } \\
\text { 4th. }\end{array}$ & \\
\hline Palm ... & $\ldots$ & $\begin{array}{l}\text { in. } \\
10\end{array}$ & in. $_{8_{2}^{1}}$ & in. $_{8 \frac{1}{2}}$ & in. & in. \\
\hline $4 \frac{1}{2}$ in above wrist & $\ldots$ & 12 & $99_{4}^{3}$ & $9 \frac{3}{4}$ & 9 & 8 \\
\hline Elbow ... & $\ldots$ & 13 & $10 \frac{1}{2}$ & $10_{4}^{1}$ & $1 C_{4}^{1}$ & 9 \\
\hline Over biceps ... & $\ldots$ & 14 & 12 & 12 & 13 & 10 \\
\hline Below acromion & ... & $13 \frac{1}{2}$ & $14 \frac{1}{2}$ & 13 & $12 \frac{1}{2}$ & $12 \frac{1}{2}$ \\
\hline
\end{tabular}

The subsequent history of the case is unsatisfactory. The old lady, who lived alone and attended to her own wants, began to use the arm very freely, contrary to the instructions given her. She was readmitted to the hospital on July lst, 1908. The swelling had to a large extent recurred, a result which is to be expected if the after-treatment is neglected. Moreover, just above the elbow one of the incisions was surrounded by an ares of redness, and had reopened, exuding a little pus, and exposing two of the buried silk threads. The skin round several other incisions was in a red and irritable condition. The infection was limited to a single pair of the threads. On July 4th this pair of threads was divided subcutaneously by a tenotome well above the elbow in a region to which the infection had not extended. The lowest incison, at the wrist, was reopened, and the infected length of silk was easily withdrawn. The track in which it had lain was syringed out with zinc chloride lotion, and the incisions were left to granulate. Nine days after operation the patient left the hospital with the incisions healed.

The infection of the silk did not occur at the first operation for the temperature, though it ran up to $101^{\circ}$ in the first twenty-four hours, fell to normal on the fourth day, and was never subsequently above $99^{\circ}$. Chronic irritation of the recently healed incisions by washing and housework appears to have been the infective agent.

I again heard of this patient in July, 1909. At this time the arm was described as enormously swollen, and quite dark in colour at the shoulder. A mass of growth, not giving rise to pain, was present in the opposite supraclavicular region.

The swollen arm was the seat of intense pain of unspecified nature. I did not have the opportunity of questioning or examining the patient.

CASE v.

Mrs. P., a lady of middle age, sent to me in 1908 by Dr. R. S. Armstrong, was operated upon for cancer of the left breast in November, 1894. A portion only of the breast was removed, and the axilla was not opened. An operation for recurrence was done in 1895. There has since besn no recurrence. Nevertheless, in August, 1907, the left arm began to swell. The arm has been "very painful indeed" and has kopt her awake at night. The swelling is only moderate in amount, but the night. The swelling is only moderate in amount, but the when restricted by pain. Lymphangioplasty was done in a nursing home on April 27th, 1908. Since the swelling was only moderate to begin with, the effect of the operation on the messurements of the arm has been almost inappreciable. Some diameters have slightly diminished, others have slightly incressed. A most marked diminution of the tissue tension of the arm was, however, manifest in a few days, and this has continued up to the present time, when all the tissues except over the back of the elbow, where there is a comparatively firm area, are remarkably soft and flabby. Although the attacks of pain in the breast, shoulder, and arm have since occurred at intervals, the patient is satisfled that she has derived great benefit from the operation.

An interesting point of the case is that this patient, who had never previously suffered from asthma, developed this disesse in a severe and typical form during her convalescence from jymphangioplasty. This fact favours the view of the pathology of asthms held by Dr. Harry Campbell and others that it depends on cedematous swelling of the bronchial mucons mem. brane. She found that the attacks were made. worse by the: elevation of the arm, and consequently she has almost negleeted. this part of the after-treatment.

Quite recently a palpable recurrence has shown itself at the apex of the axilla.

While in this case the operation has not given entire freedom, from pain, because part of it is due to pressure of growth apan. nerve trunks, it may, I think, be fairly claimed that it has arrested the evolution of what seemed to be an early stage of the typical "brawny arm." This arrest in the morbid precess. has extended to the present time, a period of twenty-one months, and during this time the pain, instead of increasing with the gradual development of the swelling, has been decidedly less than before. The tissues of the arm are soft and slack, and, in: spite of the neglect of - postural after-treatment, there:hatbeen no return of the verr marked oedema of the hand which.wag formerly present. (This patient was shown after the leoture.) .

$$
\text { Measurements of Arms. }
$$

\begin{tabular}{|c|c|c|c|c|c|c|c|c|}
\hline & & \multirow[b]{2}{*}{$\begin{array}{l}\text { Right } \\
\text { Arm. }\end{array}$} & \multicolumn{6}{|c|}{$\begin{array}{l}\text { Left Arm (not.taken before } \\
\text { Operation). }\end{array}$} \\
\hline & & & $\begin{array}{l}\text { May } \\
17 t h . \\
1908 .\end{array}$ & $\begin{array}{l}\text { Jan. } \\
8 \mathrm{tb} . \\
1909 .\end{array}$ & $\begin{array}{l}\text { Mar. } \\
19 t h: \\
1909 .\end{array}$ & $\begin{array}{l}\text { June } \\
21 \text { st. } \\
1909 .\end{array}$ & $\begin{array}{l}\text { Sept: } \\
22 n d: \\
1909:\end{array}$ & $\begin{array}{l}\text { Dee. } \\
3176: \\
1909 .\end{array}$ \\
\hline At wrist & & $\operatorname{in}_{6 \frac{5}{13}}$ & $i_{7_{16}}$ & in. & $\operatorname{in}_{68}^{5}$ & in. & $i_{6 \frac{1}{2}}$ & $\operatorname{in}_{6 \frac{8}{4}}$. \\
\hline $4 \frac{1}{2}$ in. above wrist ... & $\ldots$ & $8 \frac{1}{4}$ & $10 \frac{3}{8}$ & 11 & $10 \frac{1}{4}$ & $10 \frac{1}{8}$ & 10 & 107: \\
\hline Just below elbow ... & $\ldots$ & $9 \frac{3}{4}$ & $12 \frac{1}{4}$ & $11 \frac{1}{2}$ & $11 \frac{1}{8}$ & $11 \frac{1}{4}$ & $10 \frac{7}{8}$ & 113: \\
\hline Just above elbow ... & ... & $9 \frac{3}{8}$ & $12 \frac{8}{4}$ & - & 12 & 12 & $11 \frac{3}{4}$ & $12 \frac{13}{3}$ \\
\hline 5 in. below acromion & ... & $10 \frac{1}{2}$ & $11 \frac{1}{2}$ & $12 \frac{1}{2}$ & 123 & $12 \frac{1}{4}$ & $12 \frac{3}{8}$ & $23 \frac{1}{4}$ \\
\hline
\end{tabular}

Th1s is the only case which I have operated on in such an early stage. Although prevention is better than cure, and although the result in this case is satisfactory, it has to be remembered that cases of mild post-operative oedema of the arm do not always become progressively worse. . Since in the present case the original breast operation had been a decidedly restricted one, it can hardly be alleged as the canse of the oedema, and I am confldent that lymphangioplasty cut short the development of a typical brawny arm. But such cases will fail to convince a sceptic of the value of lymphangioplasty. They have the further disadvantage that their results cannot
be tested by measurements, and that the patient is unable to estimate the amount of pain that the operation has averted. For these reasons, and as a general rule, it is, I think, advisable for the present to defer operating until the pain and swelling have reached the stage when morphine threatens to beeome necessary for their relief. Prior to this stage the operation may be offered but should not be urged.

Case vi.

M. A. K., aged 58, in 1906 had the right breast removed for carcinoma. In October, 1907. the patient's hand and arm began to swell. The oedema steadily increased until her admission to the Middlesex Hospital under my care on May 30th, 1908. Shie suffers severe pain in the affected limb, and is unable to use it for any purpose whatever. Some thickening is present adjaeent to the scar of the breast operation and enlarged glands can be felt in the right axilla. There is no sign of visceral deposits. On June 3rd I did a lymphangioplasty. The highest subsegnent temperature was 99.4. ${ }^{\circ}$ The limb was placed on an inclinet plane. The same evening the hand had already diminished in size, and by the following morning its girth had lessened 'by $2 \frac{1}{2}$ in. On June 12 th all the wounds being soundly healed, the stitches were removed. On June 19th it is noted that the patient has had no pain since the operation, except slighty $y$ the shoulder and thumb. She left the hospital on June 30 th, greatly relieved, but died of her advancing disease on the following August 30th. (Fig. 12.)

The following table shows the subsidence of the swelling.

\begin{tabular}{|c|c|c|c|c|c|c|}
\hline & & \multicolumn{4}{|c|}{ Right Side. } & \multirow{2}{*}{$\begin{array}{c}\text { Norma1 } \\
\text { Left } \\
\text { Side. }\end{array}$} \\
\hline & & & $\begin{array}{c}\text { June 2nd } \\
\text { (before } \\
\text { Operation). }\end{array}$ & June 12th. & June 30th. & \\
\hline Hand ... & $\cdots$ & $\cdots$ & in. & $\operatorname{in}_{7 \frac{1}{2}}$ & in. & in. \\
\hline Wrist ... & $\cdots$ & $\cdots$ & $8 \frac{3}{4}$ & $7 \frac{1}{2}$ & 74 & $5 \frac{1}{2}$ \\
\hline 4 in. above & wrist & .. & $12 \frac{1}{2}$ & $8 \frac{1}{2}$ & $10 \%$ & $7 \frac{1}{2}$ \\
\hline Elbow ... & .. & $\cdots$ & 15 & $32 \frac{1}{4}$ & $\cdot 13$ & 83 \\
\hline Biceps... & $\cdots$ & $\cdots$ & $16 \frac{1}{2}$ & $14 \frac{1}{2}$ & $15 \frac{1}{2}$ & $10 \frac{1}{3}$ \\
\hline Deltoid & ... & $\cdots$ & $19 \frac{1}{2}$ & $18 \frac{1}{4}$ & 20 & 15 \\
\hline
\end{tabular}

The slight increase in the diameters between June 12th and June 30 th is due to a diminution of the daily period of elevation. 
The operation, which produced hardly any constitutional disturbance, had alreajy more than justified itself when the patient left the hospital.

Case vir

Mrs. T. was brought to me on May 13th, 1908, by Dr. J. J. Corkhill of Bouthport, with the following history. In 1897 she was operated upon for cancer of the right breast by in 1900; but later a and upon the wall of the chest, and was healed by $x$ rays. and upon the wall of the chest, sud was healed by $x$ rays. to swell at the elbow. For six months previously there had to swell at the elbow. For six months previously there had been occasionsl burning pain from the elbow to the shoulder though more constant, has not been as a rule so severe as to keep her awake. The arm has become completely paralysed, except that slight movement in the fingers remains. Two small ulcers were present in the axilla, and upon the chest there was an extensive eczematous surface with scattered nodules of growth.

For about a month a systematic attempt to get the ulcerated surfaces as clean as possible was made by Dr. Corkhill and by cataphoresis for this purpose. On June 18th, 1908, I did a lymphangioplasty at the patient's home, with gratifying results at first. A metgl spiral splint, suggested by Dr. Corkhill proved very morta I have since used it habitually until quite lately. The temperature returned to normal on the third day, and the arm rapidly subsided, with relief to the pain. On June 28th Dr. Corkhill wrote to congratulate me on the entire success of the operation. But about July 10th lymphangitis appeared, and the skin became red and inflamed. Boracic baths were used and the inflammation subsided, but left the arm as large as before the operation. On July 20 th an increase of cancerous growth was noticed. Pleural effusion showed itself shortly afterwards, and the patient died rather suddenly on August 9th. - In this case it is, I think, fair to ascribe the unsatisfactory result to the intercurrent dermatitis of the arm-a complication which I have only met with in this case.

\section{CASE vili.}

At the end of October, 1908, I was asked by Dr. W. Hall Calvert to perform lymphangioplasty at Melrose upon a patient under his care. She was a spare and delicate old lady, upon whom, seven years previously, Professor Caird of Edinburgh had operated for a cancer of the left breast. The result of the operation was satisfactory until the development of a brawny arm towards the end of 1907. When I saw her on October 30th, 1908, there was no sign of local recurrence, no any glands in the axillae. One slightly enlarged right supraclavicular gland could be felt. There was some thickening of the tigsues above the left clavicle, but no definite mass could be felt there. No evidence of visceral cancer could be found, and there was no dyspnoes-a point of considerable importance. Paralysis of the arm was almost complete. It was greatly swollen, and of brawny hardness, and caused agonizing pain which for some time past had necessitated the habitual use of morphine. The swelling of the arm did not extend to the scopular region. A bridle of skin in the line of the axillary scar prevented free abduction of the arm.

In every particular this case was an ideal one for operation especially since the disease was latent and signalized its activity only by lymphatic swelling. Evidently the defensive processes of fibrosis were very active-a fact which I believe to be con nected with the healthy open-air life led by the patient since her first operation

.With the assistance of Dr. J. M. Brydone and Dr. Calvert, I performed lymphangioplasty at once, all preparations having been previously made. At the same time a simple plastic operation was performed upon the bridle of skin which pre vented abduction. As I did not see the patient again, I cannot give a table of measurements, showing the effect produced, and I must therefore quote Dr. Calvert's letters, at the risk of appearing egotistical. On November 3rd, Dr. Calvert wrote that the temperature had never been above $99^{\circ}$, and the pulse, though quick (120), had improved. The patient felt soreness, but the pain in the arm had disappeared, and did not subsequently return. Morphine was discontinued within a few days of the operation, and was not again needed. On November 11tb, when the stitches were removed, no swelling remained except at the underside of the elbow. The patient admired her arm, which she said was "like a girl's." Her appetite and sleep were excellent, and her mental condition cheerful. Dr. Calvert concludes, and I may be forgiven for quoting his words, "I congratulate you on the splendid operation Jour scientific genius has invented."

A month after the operation the residual swelling under the elbow had quite gone, and on November 28th the patient wrote me a personsl letter of warm thanks. Unfortunately, the apparent inactivity of the disease proved to be a delusion. About four months after the operation, slight pain returned in the arm, not, however, approaching the former agony, nor requiring morphine. Swelling also began to return. Early in 1909, the left side of the chest filled up with the fluid, and dyspnoea becsme a prominent symptom. Tapping was necessary on four occasions, and each time it gave marked relief. A large mass of recurrent growth was thought to be present. The
Calvert concludes: "She was most grateful always for the relief from the agonizing pain."

Case IX.

This patient, a Red Cross nurse, aged 54, was admitted under This paith a wollen left arm on September 18th, 1908. In August, 1906, her left breast hed been excised for cancer by August, 1906, her left breast had been excised for cancer by
Mr. Andrew Clark, who subsequently, in November, 1906, removed also the right breast for cancer. In November, 1907, shortly after a motor-car accident in which her right arm was injured, this arm began to swell, gradually increasing to its present dimensions. The swelling commenced at the shoulder, and travelled downwards to the elbow and we wrist. Thelling is is extremely psinfal, especially in the axila. The swelling is greatest in the evening, better in the morning; and the pain is
also more intense at night. Secondary glands are present in also more intense at night. Secondary glands are present in ing the inner wall of the axilla, is in an eczematous condition. Specimens of blood from the left arm and of lymph from the right arm were both found to be sterile. In this case lymphangioplasty was done on September 2nd, 1908, and the patient left the hospital on September 19th with the incisions soundly healed. The swelling of the arm was, however, practically unaffected.

Measurements of Arm.

\begin{tabular}{|c|c|c|c|c|c|c|}
\hline & & $\begin{array}{l}\text { Aug. } \\
\text { 29th. }\end{array}$ & $\begin{array}{l}\text { Sept. } \\
\text { 2nd. }\end{array}$ & $\begin{array}{l}\text { Rept. } \\
\text { 13th }\end{array}$ & $\begin{array}{l}\text { Sept. } \\
\text { 18th. }\end{array}$ & $\begin{array}{l}\text { Dec. } \\
7 \mathrm{th} \text {. }\end{array}$ \\
\hline Hand $\ldots$ & $\ldots$ & $\begin{array}{l}\text { in. } \\
7 \frac{1}{2}\end{array}$ & in. & $\operatorname{in}_{7 \pm}^{1}$ & $\begin{array}{l}\text { in. } \\
7_{\frac{1}{4}}\end{array}$ & ${ }_{8 \frac{1}{2}}$ \\
\hline Wrist $\ldots \quad \ldots$ & ... & $7 \frac{1}{4}$ & $7 \frac{1}{2}$ & $7 \frac{1}{4}$ & $7 \frac{1}{8}$ & 8 \\
\hline 4 in. abore wrist & $\ldots$ & 9) & $9 \frac{1}{4}$ & 91 & 9 & $10 \frac{1}{4}$ \\
\hline Elbow ... & ... & $12 \frac{3}{4}$ & 13 & $12 \frac{1}{4}$ & $12 \frac{3}{8}$ & $12 \frac{5}{8}$ \\
\hline in. above ulbow & ... & 13 & $12 \frac{1}{4}$ & $12 \frac{1}{2}$ & $12 \frac{1}{2}$ & 12 \\
\hline
\end{tabular}

About October 10th, 1908, this patient began to feel shortness of breath, and she was admitted to the cancer wards, under Mr. Murray, on November 10th. When I saw her next, on December 10th, clo:ely-set subcutaneous nodules of growth were present round the posterior axillary fold, and lines of small similar nodules radiated thence roupd the back, definitely following and mapping out the track of the silk threads, at the ends of which the nodules ceased. She had experienced no relief from the operation. The right chest was full of fluid and the dyspnoea was severe. She died before the end of 1908.

Evidently in this case the silk threads had been passed through a region where active cancer cells were present, and had carried with them cancerous infection down the subcutaneous tissue of the back. This is the only case where I have met with such a complication. It is to be avoided by a rigorous selection of cases and by keeping away from the region of the axilla, carrying the silk threads from the arm to the back over the posterior fibres of the deltoid muscle. Under no circumstances must the threads be carried through a region of obviops cancerous infiltration.

CaSe $x$.

Mrs. N., aged 61, was sent to me in August, 1908, by Dr. R. T. Bedford of Fulham. In August, 1904, a cancer was exciser from the right breast at Dorchester Hospital. In April, 1908 she began to suffer very severe pain in the right arm. She had previously been able to use the arm quite naturally, and there was no sign of recurrence anywhare. Three weeks after the pain began the arm commenced to swell, and has since gradually increased in size. The patient continued to work hard as usual until July, 1908, when she was compelled to give up. In the following month the pain and swelling diminished to some extent.

The arm, which is much swollen, pits slightly on pressure, though the oedema approaches the solid variety. There is no paralysis. The swelling first began over the triceps and travel led gradually downwards. The hand is even now only slightly affected, though it becomes much paffed towards night. "funny bone" (ulnar nerve). At other times it is like a succession of stabs. It comes on in paroxysms, and sometimes she has a whole night free from it. Decided fullness is present below the clavicle. This appesrs to indicate recurrence in the subclavian glands. An examination of Jymph and blood drawn from the arm shows that micro-organisms are absent from it. On September 5th lymphangioplasty was performed and a normal convalescence followed, the patient leaving the hospital on September 28th. But for reasons which I am unable to explain, the operation failed to benefit either the pain or the swelling. One can only conjecture that, for some reason or other, there was no adequate return flow of lymph from the region to which the silk threads were led.

\section{CASE XI.}

Mrs. N., a lady of advanced middle age, consulted Dr. $N$. Henry Hobart of Cork, on June lst, 1908 , for a carcinoma of the upper and outer quadrant of the left breast, about the size of an orange. The lump had been noticed only ten days previously, and had never caused pain. The skin was somewhat adherent. The breast and pectoral muscles were removed 
without delay. Healing took place by first intention, and the patient was moved to her home on the sixteenth day. She was next seen on September 19th, and a small nodule was found to the left of the scar, halfway between the axilla and the line of the nipple. This was removed on September 19th, and the granulating surface left was not completely healed until the middle of November. About this time the left arm commenced to swell, and she began to suffer considerable pain in the arm. The pain, which became very severe, was referred chiefly to the palm of the hand. Her condition became gradually worse, and the arm was closely bound to the side by the contraction of the parts. On December 23rd Dr. Hobart asked me to see the patient with him, and lymphangioplasty was performed at her home on the following day. The subsequent after-treatment was made rather difficult by the very limited abduction and flexion allowed to the arm by the axillary contraction. Owing to the distance of the patient's home from liondon, I did not see her again, and I am unable to express the result of the operation in measurements. Dr. Hobart has, however, kindly supplied me with details of the further history of the case. The swelling of the hand completely disappeared within eighteen hours and pain in the limb had gone. On January 3rd, 1909, there was a slight return of the swelling in the hand. Two days later it had again disappeared, but there was a certain amount of "pitting" in the upper part of the arm, chiefly in its anterior surface. Elevation and extension of the arm were too irksome to be completely carried out, and after the first week the arm "Was simply laid on a pillow. Dr. Hobart states at this time enormous relief you have afforded her."

Six weeks after the operation it became impossible, owing to the advance of the growth in the axilla and chest, to move the arm in any direction, all attempts at elevation had to be abandoned, and morphine in small repeated doses became necessary. The forearm began to increase in size again towards the end of January, and later the upper arm, but the hand remained sbout of normal size until the second week in April, three weeks before death. Swelling then began on the dorsum, but the palmar swelling, which had been so painful, did not recur. Towards the end of February the supraclavicular glands becam intensely hard, and caused considerable pain. At the end of March it was evident that the pleura was attacked. Abont April 8th the patient became suddenly delirious, and in her struggles a large quantity of serous fluid ( $30 \mathrm{oz}$. approximately) suddenly poured down the arm from the region of the axilla. Her mental condition remained seriously affected until the end, which came from exhaustion on April 30th, 1909. Dr. Hobart says in conclusion: "I know of course that in this case you were greatly handicapped by the condition of the parts, bu I am quite confident that your operation afforded Mrs. a very great amount of relief. Her greatest pain, due to swelling, lay in the palm of her hand. She never again suffered from this or the tense fullness of the arm; any pain she had was in the shoulder and chest, which of course was not affected by jour operation.'"

Case XII.

Mrs. S., aged 57, living in Colorado, U.S.A., was brought to London in December, 1908, by her medical advieer, Professor Lloyd Miller, of Greeley, Colorado.

Her history was as follows: In 1895 Professor Miller success fully removed the right breast for cancer. Recurrence at the end of four years was treated by caustics, and the disease becsme quiescent. However, in 1907, twelve years after the primary operation, the right arm became brawny and extremely painful. In June, 1908, a Denver surgeon performed lymphangioplasty. Six threads were introduced, and still remain in position. The threads consisted of cosrse silk twist, and were led from the wrist and along the inner aspect of the arm to the front of the shoulder, and thence to terminate over the posterior triangle of the neck. The operation temporarily reduced the swelling of the arm, but considerable swelling persisted, and the pain remained sufficiently severo to cause habitual insomnia, to require the habitual administration of morphine, and to induce the patient to cross the Atlantic in the hope of relief.

Upon examining the patient I found the case a favourable one for operation in regard to the absence of pleural effusion and of ulceration over the chest. The arm could be freely abducted, though movement of it aggravated the pain. One small nodule of growth was present on the side of the chest below the axilla.

In the right supraclavicular region the glands were slight]y enlarged, especially one behind the sterno-mastoid. At the back the tissues nearly down to the angle of the scapula showed some oedematous hardening, but no nodules vere present. It was evident that the lymph drainage provided by the first lymphangioplasty was partial and imperfect. None of the threads were carried along the back of the arm, which remained undrained. It was here accordingly that the principal swelling was located. The threads in front were carried to a region dangerously close to the area of operation. Here, along the coraco-brachialis and in the line of the threads was an indefinite hard band of tissue, which I suspected to be caused by cancerous infiltration along the threads. The pain felt by the patient was sometimes referred to this region, but it was mainly and usually a heavy diffuse pain felt all over the arm. The arm was nearly paralysed.

It appeared to me that some of the pain might depend apon nerve pressure, but that it was mostly due to fluid tension in the tissues. I accordingly advised a more complete lymphangioplasty as promising considerable relief from swelling, pain, and insomnia. The operation was performed on December 27th 1908 , the anaesthetic being given by Mr. H. P. Noble. In view of the possibility of cancerous infiltration in the line of the coraco brachialis, this region was carefully avoided. Otherwise the operation was performed as usual, save that as there was some oedematous thickening over the scapala some of the threads were led further down than usual, terminating in the lumbar region, while others were led across the middle line of the back to terminate over the opposite scapula.

As usual, marked and fairly rapid subsidence of swelling followed the operation. Relief of pain, however, was slow. in coming, and insomnia remained troublesome. These nuusual features of the case appeared largely due to the patient's neurasthenic condition, produced by long-continued chronic pain, and aggravated by the morphine necessary for its relief At times her condition bordered on melancholia, and she temporarily lost the wish to live.

Morphine was only given twice subsequently to the operation. A tablespoonful of vibrona at bed time and a course of aspirin were substituted for it, and although the accustomed sedative was at first acutely missed, sleep gradually improved and pain diminished. Dr. Lloyd Miller's co-operation in the after treatment of this difficult case was invaluable. A course of $x$ rays to the region where growth was suspected was given by. Mr. appeared to benefit the pain in the coraco-brachialis region which was still troublesome at times.

The arm subsided slowly and continuously. The patient left the home on January 21st, 1909, to return to America.

The measurements of the arm were as follows:

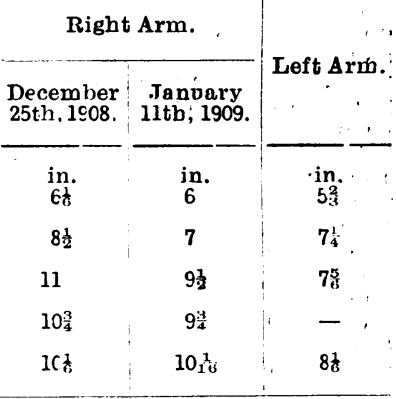

In this case, as in some others, the measurements do not give a fair idea of the effect of the operation. A small diminution in calibre, or even no diminution at all, may be accompanied by a the arm which was hard becomes soft and flabby. Buch was the cose in the present instance.

When Mrs. S. left the home sbe sti]l had occasional pain in the arm, but on February 27 th Dr. Miller was able to write that the swelling of the arm had entirely disappeared with the exception of a slight soft swelling at the shoulder, which cansed no discomfort. Pain had all left the arm and hand, and she was sleeping well from night to morning, a thing she had not been able to do for more than a year previous to the operation. Her mental condition was contented and happy. Dr. Miller's letter concluded with a very favourable estimate of the value of lymphangioplasty, which I forbear to quote, leaving the case to speak for itself. On April 26th, in another letter, he said, "Mrs. S. is still doing fine."

\section{CASE XIII.}

On April 22nd, 1909, I saw at Norwich with Dr. H. J. Starling, lady aged 40 and unmarried, with the following history: In July, 1908, she was operated on for scirrhus of the right breast. The following November she was again operated on for a recurrence near the scar. In January, 1909, $x$ rays were applied for month for further recurrence in the scar on the advice of care of Dr. Starling. At this time she had pain all over the right breast, and increasing very painful oedema of the whole of the right arm, with great dyspnoea and deficient air entry to the right lung. The daily use of morphine was necessary, together with inhalations of oxygen.

The case was obviously one in which death was not far distant, and one in which the risk of the ansesthetic could not be overlooked. But as the skilled services of Dr. Starling were available for the anaesthetic, and as the sufferings of the patient were extreme, I felt that the operation could be offered to the patient if the pleural fluid in the right sac could be safely removed. This was done, and the operation performed immediately afterwards. There was considerable shock owing to the patient's weak condition; bat the wounds healed by first intention, and pain and swelling disappeared from the arm and hand. Subsequently the pleura had to be tapped on several occasions, and the patient went downhill rapidly. Swelling did not return to the hand, forearm, or lower part of the arm, but it appeared in the axilla, and extended across the chest to the left breast. She died about May 24th. I did not see the patient subsequent to the operation, but in Dr. Starling's "opinion, expressed recently in reply to a letter from me, it was unhesitatingly recommend the operation again in such a condition as was hers." 
CaSE XIV.

This lady, aged 37, was sent to me by a well-known surgeon who had operated for carcinoma of the left bresst about two Jears previously. Closely following apon the shock of the death of - near relative from cancer, recurrence made its appearance on the side of the chest and in the supraclavicular region, while a vague induration appeared in the axilla. Radium treatment was applied in Paris, without much benefit. About the end of April, 1909, swelling of the arm became very marked, and pain and discomfort from this cause began. Radium treatment was recommended by Dr. Louis Wickham for this condition, but the patient herself felt that the applications aggravated the swelling. Radium treatment was continued in Fingland after the patient's return. She continued, in spite of her sufferings, to lead an active life, and although her condition would have confined most women to bed, she frequently spent a whole day in the hunting field, carrying the swollen arm on the saddle in front of her. Her determination to fight and conquer the disease was truly heroic. She had noticed that confinement to the house seemed to quicken the march of the disease- a fact she had observed during an attack of mumps early in 1909-and had lived an active open-air life in consequenoe. I first saw her on August 28th, 1909. She had then an indolent, ulcerated, or rather eczematous, cancerous area over the front and side of the left chest, one or two very large glands in the supraclavicular region, and a vague induration in the armpit. There was also some impairment of resonance at the base of the left lung. She had had attacks of shortness of breath. The arm was hard, cyanotic , and very swollen, the swelling extending up to and involving the shoulder, but not at that time covering the scapular region.

I pointed out that the case was not a favourable one for $m y$ operation, in view of the activity of the disease and the doubt as to the condition of the pleura. The patient and her husband were, however, most anxious for the performance of lymphangio. plasty, even if the relief would last "only three days." The case seemed to be one where the wishes of the patient could be allowed the deciding voice, and on August 29th I operated by the usual method.

The immediate result was most striking and satisfactory. The pain ceased from Angust 30th, and the hand and forearm rapidily subsided and regained their normal colour, while the tension of the upper arm was much diminished, and it became comparatively flabby. Movement also returned to the fingers, wrist, and elbow. The stitches were removed on September 6th, when all the incisions were soundly healed. The only incident in a smooth convalescence was an alarming attack of dyspnoen, necessitating the use of oxygen, which occurred about the fifth day. The patient went down to dinner on September 6th, and at this time her only trouble was sleeplessness. On September 9th she motored 60 miles into the country and though rather exhausted everything seemed going well. From this time, however, the swelling in the arm rapidly recurred. On September 18th I found on examination much fluid in the pleural cavity, and drew off a quart of strawcoloured effusion. The cancerous area in front of and at the side of the thorax had rapidly extended and was involving the scapular region, to which the threads had been led, blocking up the new lymphatic drainage system. On September 25th the arm was as bad as before the operation, and there was oedema over the whole front of the chest and the left supraclavicular region. The patient's mental attitude had changed from one of eager fight to one of serene resignation. From this time morphine w\&s administered regularly, and the patient died in December, 1909 .

It may be said that in this case the operation was unjustifable. This opinion would ignore the patient's imperative wish to have it tried and the subsequent period of ease, which, though measured by days, must have been an unspeakable relief after months of torment. The respite could have been obtained by no ather method with which I am acquainted. The surgeon who removed the growth went to see the patient some days after the operation, and expressed himself satisfled that the operation had justified itself.

Case Xv.

A.T., aged 54, was admitted into the cancer wards of the Midalesex Hospital on September 25th, 1909. In 1899 a nodule was excised from the right breast. In 1902 the breast was remored for local recurrence. In 1904 five nodules appeared near the scar, and ulceration supervened later, but healed under $x$ rays in 1908, only to break out again later. Growth and vloeration appeared in the axilla, but pain remained absent until the development of a dropsical right arm sbout June, 1909.

On. admission in September, 1909, she was very ill and cachectic, with extensive nodular growth, in places ulcerated, over the sternum and right chest wall. The axilla was a deeply nicerated chasm with a floor of offensive sloughy growth. On December 2nd, at the patient's earnest wish, I consented to do lymphangioplasty if the ulcers could be got into a cleaner condition. For this purpose the axillary cavity was filled with acetone for half an hour daily. The application was painfal, and on December 18th a severe haemorrhage of about a pint occurred from the axillary cavity, with slight temporary beneft to the swelling of the arm. On January 8th, 1910, the general condition showing some improvement, lymphangioplasty was performed in the usual manner.

The operation caused me a considersble amount of anxiety, for the axillary ulcer, apreading from the front, had left only through this narrow strait the silk threads had to be led. The risk of failure had been fully explained to the patient, and she desired to submit to it rather than remain in her condition of pain and misery. Fortunately, no failure of asepsis occurred, a fact which reflects great credit on the house-surgeon, Dr. A. $O$. English, and on the nursing staff, and her convalescence was without incident. Although the contraction of the axillary tissues allowed of no abduction and only the slightest elevation it was noted on January 14th that the hand and forearm had much improved, and the skin of the hand showed marked creasing. The arm had not much diminished in size. On January 19th the registrar notes "There is very great improvement in the condition of the arm. Swelling in the hand and arm has diminished wonderfully." Before the operation the hand and arm and even the fingers were quite paralysed, while the patient can now move both the wrist and elbow, and can grasp firmly with the hand. The patient especially drew my attention to the increased vertical mobility of her shoulder and to the diminution of swelling behind the shoulder-joint.

On January 23rd, in a letter written tc me with the hand which had been completely paralysed, she expressed herself delighted with the results of the operation, especially in regard to the relief of pain. In order if possible to check the advance of the disease in the direction of the threads, a course of $x$ rays is being applied to the region of the scapula.

The measurements of the arm are as follows :

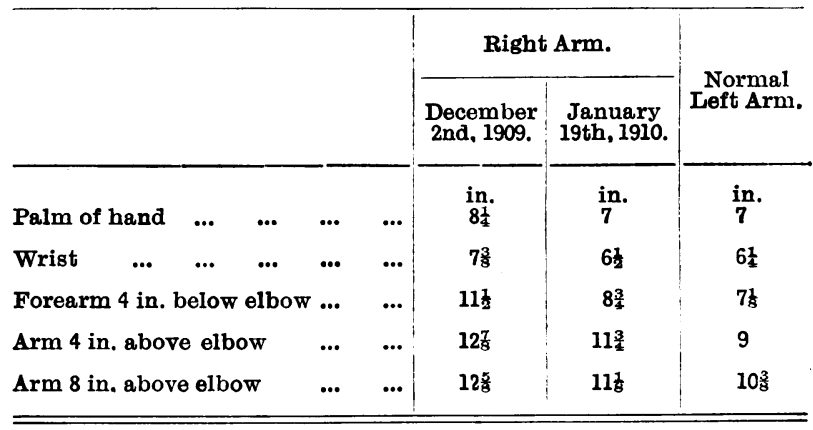

\section{Kemark:}

ON A

\section{CASE OF RECURRING JAUNDICE IN FOUR SUCCESSIVE PREGNANCIES, WITH FATAL JAUNDICE IN THREE SUCCESSIVE INFANTS.}

By H. D. ROLLESTON, M.D., F.R.C.P.,

SENIOR PHYSICIAN, ST. GEORGE'S HOSPITAL; PHYSICIAN, VICTORIA HOSPITAL FOR CHILDREN.

A wOMan who had never had jaundice at any other time had jaundice in her four successive pregnancies, and her first three infants died of jaundice. In the fourth pregnancy the woman was treated with urotropin and sodium salicylate, and, though she became somewhat jaundiced about the sixth month, she had a healthy child.

A married woman, aged 35, two months pregnant, came to St. George's Hospital on December 8th, 1908, in order to see if anything could be done to prevent the sequence of events which had characterized her three previous pregnancies. In each of these pregnancies she had become jaundiced about the sixth month, and subsequently suffered from itching of the skin. Throughout all her pregnancies she has had nausea, but has never had vomiting. She is always constipated, and this is much worse during her pregnancies. Her three children were all born six weeks before term, and, though not janndiced at birth, rapidly became so, and died; the first, a boy, died at 5 months; the second, also a boy, at 5 months; and the third, a girl, at 16 days. She has not been able to suckle any of her children. She has never had jaundice or pruritus except during these pregnancies; she has not had biliary colic or enteric fever; and, as far as she knows, jaundice has not occurred among her own relations or in her husband's family.

During her fourth pregnancy she was treated with urotropin and salicylate of sodinm, with a view of preventing infection and obstraction of the biliary tract, and the occurrence of grave jaundice in her infant. This, however, was not entirely successful, for she became jaundiced about the sixth month, and had pruritus, though she did not feel so uncomfortable as in her previous pregnancies. There was no enlargement of the liver or spleen. On June 3rd, 1909, a healthy 8 months boy was born. He did not show any sign of jaundice; when $2 \frac{1}{1}$ weeks old he was admitted into the hospital. There was nothing really the matter with him; the liver, spleen, and urine were healthy. He was seen again on March lst and 10th, 1910, when he weighed $16 \mathrm{lb}$.. and was in very good heslth. He has never had any jaundice. 